NBER WORKING PAPER SERIES

\title{
INTERRACIAL WORKPLACE COOPERATION: EVIDENCE FROM THE NBA
}

\author{
Joseph Price \\ Lars Lefgren \\ Henry Tappen \\ Working Paper 14749 \\ http://www.nber.org/papers/w14749
}

\author{
NATIONAL BUREAU OF ECONOMIC RESEARCH \\ 1050 Massachusetts Avenue \\ Cambridge, MA 02138 \\ February 2009
}

We would like to thank Jeff Desimone, Scott Hankins, Fidan Kurtulus, Alex Mas, and Abigail Wozniak for helpful comments and Matt Gibb for excellent research assistance. The views expressed herein are those of the author(s) and do not necessarily reflect the views of the National Bureau of Economic Research.

NBER working papers are circulated for discussion and comment purposes. They have not been peerreviewed or been subject to the review by the NBER Board of Directors that accompanies official NBER publications.

(C) 2009 by Joseph Price, Lars Lefgren, and Henry Tappen. All rights reserved. Short sections of text, not to exceed two paragraphs, may be quoted without explicit permission provided that full credit, including (๑) notice, is given to the source. 
Interracial Workplace Cooperation: Evidence from the NBA

Joseph Price, Lars Lefgren, and Henry Tappen

NBER Working Paper No. 14749

February 2009

JEL No. J15,J71,L23

\section{ABSTRACT}

Using data from the National Basketball Association (NBA), we examine whether patterns of workplace cooperation occur disproportionately among workers of the same race. We find that, holding constant the composition of teammates on the floor, basketball players are no more likely to complete an assist to a player of the same race than a player of a different race. Our confidence interval allows us to reject even small amounts of same-race bias in passing patterns. Our findings suggest that high levels of interracial cooperation can occur in a setting where workers are operating in a highly visible setting with strong incentives to behave efficiently.

Joseph Price

Department of Economics

Brigham Young University

162 FOB

Provo, UT 84602

and NBER

joseph_price@byu.edu

Lars Lefgren

130 Faculty Office Bulding

Brigham Young University

Provo, UT 84602-2363

1-lefgren@byu.edu
Henry Tappen

130 FOB

Provo, UT 84602

htappen@gmail.com 


\section{Introduction}

Recent research shows that when individuals are forced to make quick decisions, they often exhibit same-race preferences, even if they are unwilling to admit to biased racial attitudes. For example, Price and Wolfers (2007) show that NBA referees are more likely to call fouls against players of a different race than players of their own race and Parsons et al. (2008) find that umpires are more likely to call strikes for pitchers of their own race. Similarly, Antonovics and Knight (2005) find that police are less likely to search the vehicle of someone of their own race and Donohue and Levitt (2001) find that an increase in the number of police of a certain race is associated with an increase in arrests of people of the other race.

This same-race bias could play an important role in collaboration among colleagues in a workplace. For example, managers might be more likely to give favorable assignments to same-race employees. Alternatively, colleagues may depend disproportionately on same-race colleagues for advice or help. Collectively, such decisions may reduce the workplace productivity and satisfaction of employees of a minority race. These decisions may play a role in explaining the extent of workplace segregation (Hellerstein and Neumark 2008). Furthermore, this bias would undermine the argument that productivity is higher in groups that are ethnically diverse (Page 2007).

In this paper, we examine the effects of group heterogeneity on teamwork by studying specific and measurable actions within teams. In traditional firm-level data, it is often difficult to obtain measures of cooperation. As a result, we use play-by-play data from the National Basketball Association (NBA). These data allow us to determine for each basket completed who passed the ball and which other players were on the court at 
the time. We develop a simple model which allows the optimal pass to depend on the particular combination of teammates on the floor. We then test whether the pattern of observed assists demonstrates evidence of same-race bias.

We find no evidence that, conditional on the set of teammates on the court, players are more likely to pass to a teammates of their same race. Our baseline empirical strategy controls non-parametrically for the joint distribution of shot quality for all teammates on the floor. In other words, we account for differences in ability across teammates. Furthermore, the shooting opportunities of one teammate are allowed to depend arbitrarily on the set of other teammates on the floor. Robustness checks, in which we reduce the flexibility of our empirical specification to increase statistical precision, yield the same substantive results. Our evidence suggests that in workplaces where employees have common goals and extensive experience working with each other, cross-race cooperation may not be a problem.

\section{Similarity and Cooperation}

There is considerable research, both empirical and theoretical, indicating that diversity can lead to improved economic outcomes (Alesina and La Ferrera 2005; Hong and Page 2004; Alesina, Spolaore, and Wacziarg 2000). These gains from diversity depend on the various groups being willing to cooperate. This may explain why other studies have found that increased racial diversity is associated with lower group performance (Kurtulus 2008; Timmerman 2000). In this paper, we expand the literature on the effects of group heterogeneity on outcomes by studying specific and measurable actions within teams. 
Our analysis of cooperation is one form of own-race bias that has been documented in other types of interaction including referee-player (Price and Wolfers 2007; Parsons et al. 2008), employer-employee (Stoll, Raphael, and Holzer 2004) and officer-offender (Antonovics and Knight 2004, Donohue and Levitt 2001). What distinguishes cooperation from these other settings is that players are working together towards a common objective, while these other settings involve a more adversarial relationship. In addition, there is research showing that the racial composition of one's group affects decisions similar to cooperation, such as willingness to provide a public good (Martinez-Vazquez, Rider, and Walker 1997), form a coalition (Brasington 1999), or increase welfare spending (Luttmer 2001).

\section{NBA Data}

Our analysis draws on play-by-play data that we collected from espn.com for all regular season and playoff games during October 2002-June 2008. The data includes an entry for every occurrence during the game that might be important for compiling gamelevel statistics. For each shot that is completed on the court, the data provide the name of the person who shot the basket and the person who was awarded with an assist, if the shot was assisted (58.9\% are). Using times of substitutions in the data, we apply recursive methods to determine the ten players on court at any given time.

Thus, for each assisted shot we know who the passer was and the set of four players would have been available to receive the pass. For each of these players we merge in information about their race, position, and other characteristics. The player's race information comes from data collected by Kahn and Shah (2005), Price and Wolfers 
(2007) and our own coding from more recent online photos of the players. Our racial coding is based on a simple measure of "black" or "not-black."

Table 1 shows summary statistics from our sample. White players completed 36.7 percent of the shots and 20.3 percent of the passes in our sample. ${ }^{1}$ Separating the probability that the shooter is white based on the race of the passer (as done in columns 2 and 3) provides an initial estimate of racial gaps in passing. A white passer is 3.89 percentage points more likely to complete an assist to a white shooter than is a black passer (the t-statistic for this difference is 12.4). This simple estimate fails to capture any clumping of white players on the same team (or on the court together) or differences in the positions they play.

As additional controls for our analysis, we include information about the passer's position, how many years he has been on the current team, whether or not the pass occur during the fourth quarter of a game in which one of the teams is ahead by more than 15 points at the start of the fourth quarter (a blowout game), and whether or not the pass occurs at a time in the fourth quarter when in which one of the teams is ahead by no more than 4 points (a close game).

As part of our empirical strategy, we construct identifiers for each unique group of four players available to receive a pass on a particular play. We limit our analysis to passing opportunities in which there was at least one player of each race available to receive the pass. This eliminates about $48.1 \%$ of our observations for situations in which the four players available to receive the pass are black and another $4.36 \%$ of our

\footnotetext{
${ }^{1}$ These are an overestimate of the actual fraction of passes and shots made by white players because our sample is limited to observations in which there was at least one player of each race available to receive the pass. Without this restriction, white players would make $21.2 \%$ of the shots which is roughly in line with their representative in the NBA.
} 
observations when those four players are white. Including these observations in our sample would bias our estimates of own-race discrimination towards zero, since the passer in these situations has no choice regarding the race of the player he can pass to.

\section{Model and Empirical Strategy}

Before progressing to our empirical specification and findings, it is helpful to outline a simple economic model of cooperation. Basketball involves complex offensive and defensive strategies. For this reason, we define a simpler game that will highlight the intuition involved and suggest an empirical strategy for identifying possible same-race bias in passing patterns.

Consider a game with five players. One of the five players is initially endowed with the ball. The player then passes the ball to one of the four remaining players with the best shot at the basket. We define $S$ as the set of four players available for the pass. Player $i \in S$ has an opportunity for shot, the quality of which is given by $\mu_{i}$. Player $j \in S$ is another player in the passer's choice set with shot quality $\mu_{j}$. We do not assume that $\mu_{i}$ and $\mu_{j}$ are independent or identically distributed. We do, however, assume that both are independent of the player passing the ball. We assume that the player with the ball passes to his teammate with the highest quality shot. Given these 
assumptions, the probability that the player with the ball passes to player $i$ given the set of available passing options, $S$, can be written $\theta_{i, S}=\operatorname{prob}\left(\mu_{i}>\mu_{j} \forall j \neq i \in S\right) .^{2}$

This simple model suggests a tractable empirical specification to test the role of race in on-the-job cooperation. We can estimate the following linear probability model:

$$
1_{S, p}^{\text {scorer }=\text { white }}=\theta_{w, S}+\beta 1_{S, p}^{\text {assister }=\text { white }}+\varepsilon_{p},
$$

Where $1_{S, p}^{\text {scorer=white }}$ is an indicator variable that takes on a value of 1 if the player scoring the basket is white, given the set of available scorers $S$, during possession $p . \theta_{w, S}$ is estimated by a set of dummy variables for every combination of four players available to receive the assist. This controls non-parametrically for the probability that a white player has the best shot, taking into account the joint distribution of shot quality among all players eligible for a pass. Thus, $\theta_{w, S}$ accounts both for the talent of every player available for a pass, as well as how the players interact while on the floor together. $1_{S, p}^{a s s i s t e r=w h i t e}$ takes one a value of 1 if the player making the assist is white and $\varepsilon_{p}$ is the residual.

Identification arises from the fact that both a white and a black player choose among the same set of teammates when passing the ball. If white and black passers are solving the same optimization problem with the same constraints, $\beta$ should be statistically insignificant from zero. A non-zero coefficient suggests that the race of the

\footnotetext{
${ }^{2}$ As an example of this, consider the case where $\mu_{i}=\bar{\mu}_{i}+\varepsilon_{i}$, where $\bar{\mu}_{i}$ represents fixed player ability and $\varepsilon_{i}$ is distributed according to a Type 1 extreme value distribution. In this case, the probability that the ball is passed to player $i$ is given by $\operatorname{prob}\left(\mu_{i}>\mu_{j} \forall j \neq i\right)=\frac{\exp \left(\bar{\mu}_{i}\right)}{\sum_{j=1}^{4} \exp \left(\bar{\mu}_{j}\right)}$.
} 
passer and potential scorers affects the pattern of assists and hence on-the-job cooperation.

The disadvantage of our preferred approach is that it consumes literally tens of thousands of degrees of freedom since we include separate fixed effects for sets of players that differ only by a single role-player. In doing so, we discard large amounts of potentially useful information. To the extent that we can approximate $\theta_{w, S}$ without the inclusion of so many dummy variables, we will increase the precision of the estimated same-race bias.

To do so, we calculate the fraction of assisted baskets scored by a player while on the floor, excluding baskets in which that player made the assist. This is calculated separately for each season. For player $i$, we denote this probability $\hat{\pi}_{i}$. One potential proxy for $\theta_{w, S}$ is given by:

$$
\hat{\theta}_{w, S}^{\text {proxy1 }}=\sum_{i \in W \cap S} \hat{\pi}_{i},
$$

where $W$ is the set of white players and $S$ is the set of potential pass recipients on the court. While this measure is simple, it fails to take into account any interactions between players on the court. A symptom of this is that even if all potential pass recipients were white, the measure would almost certainly be above or below one.

For this reason, we construct a second proxy by normalizing this measure by the propensity of all players in the choice set to score off an assist. Our second proxy is given by:

$$
\hat{\theta}_{w, S}^{p r o x y 2}=\frac{\sum_{i \in W \cap S} \hat{\pi}_{i}}{\sum_{j \in S} \hat{\pi}_{j}} .
$$


This has the advantage that if all potential pass recipients were white, the measure is constrained to equal one. It also takes into account that a player's probability of scoring depends on the skill of the other teammates on the floor. It fails to take into account, however, all of the possible idiosyncratic interactions between teammates the way our preferred approach does.

Using the second of these two proxies, we supplement our primary findings by estimating linear probability models of the following form ${ }^{3}$.

$$
1_{S, p}^{\text {scorer }=\text { white }}=\alpha_{0}+\alpha_{1} \theta_{w, S}^{\text {proxy } 2}+\beta 1_{S, p}^{\text {assister }=\text { white }}+\varepsilon_{p}
$$

If our proxy performs well, we would expect our estimate of $\alpha_{1}$ to be close to one.

Under the null hypothesis of no same-race bias, we would still expect $\beta$ to be close to zero. $^{4}$

One concern with all specifications is that we have data on only completed assists. Thus, we cannot determine passes that were made that did not lead to shots and potential assists that were not converted. While these possibilities could affect the apparent magnitude of same-race bias, they do not affect the sign of the coefficient. Suppose a player systematically passes to teammates of his own race, even though they have worse shots than teammates of another race. In this case, assists between players of the same race will be relatively more common than assists between players of differing races. This difference in assists will be less than the difference in attempted assists, however, because passes made for race-based reasons will be less likely to lead to converted

\footnotetext{
${ }^{3}$ We also estimate all of regressions using logit (table 3 ) and conditional logit (table 2) regressions. The marginal effects and standard errors are nearly identical to those using linear probabilitiy models.

${ }^{4}$ In all specifications, we cluster correct the standard errors at the team level. This takes into account that passing decisions may not be independent across assist opportunities. For example, a particular player may consistently look to pass to a certain teammate for reasons independent of the race of the two players.
} 
baskets. When players choose to score alone or make a pass to a teammate out of position to score instead of assisting to a teammate of a differing race, this also increases the relative frequency of same-race assists. Thus data limitations may affect the magnitude of the observed same-race bias, but our procedure still provides a valid test for the existence of same-race passing preferences.

\section{Findings}

Table 2 shows the results from our empirical examination using our baseline method. The first column shows our baseline specification with fixed effects for each of the four player combinations but no additional covariates. We find that the probability that the shooter is white increases by 0.97 percentage points relative to a baseline probability of 36.7 percentage points (or a $2.6 \%$ increase) and is not statistically significant. Even at the upper end of the $95 \%$ confidence interval, a white passer is only 2.5 percentage points more likely to pass to a white teammate than a black passer. ${ }^{5}$

In the second column, we include additional controls for the position of the passer. This addresses the concern that differences in the position mix between black and white players may lead to differences in passing patterns that are unrelated to preferences. The resulting coefficients are virtually identical to the baseline estimates.

In the third column, we interact the race of the passer with a dummy variable indicating whether or not the passer is in his first year on the team. This tests the

\footnotetext{
${ }^{5}$ While we find no effect of same-race bias in passing patterns, an apparent effect would not necessarily indicate on-court animus. Instead, a high incidence of within race passing might indicate familiarity between players of the same race. In other words, a white player might be happy to make a pass to a black player in position to score but instead passes to a white teammate because he knows better where that teammate will be on the floor. In this case, race-based social investments off the court translate into low levels of cross-racial cooperation off the court. While the proximate cause of the racial bias differs, the ultimate consequence is the same.
} 
hypothesis that as a passer becomes more familiar with his teammates, he will show less same-race bias. The coefficient on the interaction between race and the first year on team dummy is extremely small (-1.5 percentage points) and is not statistically significant.

In the fourth column, we examine a set of possessions in which one team is more than fifteen points ahead of another in the fourth quarter. In such cases, because the outcome of the game is already determined, players may be more willing to make inefficient passes to same-race teammates. When we estimate our model with such a specification, we find that the coefficient becomes about nine times as large but much less precisely estimated. The coefficient indicates that, in these settings, white passers are about 9.1 percentage points more likely to pass to a white shooter. This estimate is not statistically significant and given the large standard errors, we cannot reject that this coefficient is the same for the full sample. However, the results suggest that racial bias may occur when the outcome of a particular task is no longer dependent on the worker's decisions.

We also perform a similar analysis on shots made during fourth quarter when the score is within four points. In contrast to blowout games, players in such situations may be willing to put aside racial bias in order to win the game. Indeed, we find that the coefficient is one-third as large as in our baseline specification, although much less precisely estimated.

Table 3 shows estimates of alternative specifications in which we approximate $\theta_{w, S}$ as shown in equation (3). As expected, we find that our estimate of $\theta_{w, S}$ is close to one, indicating that our constructed measure is a good proxy for the probability that the assist recipient is white. Our test of own-race bias is based on whether deviations from 
this predicated probability are influenced by the race of the passer. We find no evidence of a preference by players to pass to players of their own race. Our estimate in the first column indicates that the probability that a white player receives an assist is only 0.09 percentage points higher when the passer is white than when the passer is black. This difference is even smaller when we control for the position of the passer.

In the third column, we test whether this measure of same-race bias changes as players are with the same team longer. There is little evidence that this occurs. In the fourth column, we look at the blowout games and find a very small negative coefficient (the opposite of same-race bias) that is imprecisely estimated. Finally, in the fifth column, we examine close games and discover a large positive coefficient that is also imprecisely estimated.

\section{Interpretation and Conclusion}

Assist patterns in the NBA exhibit very little evidence of same-race bias. More specifically, given a particular set of players on the court, a white passer is no more likely to pass to a white teammate than a black passer. While this result is interesting, it is important to note why the high degree of interracial cooperation may be specific to the NBA.

Our model can be thought of as the final node in a more complex game in which players are matched to teams and coaches decide which players are on the floor and which plays are run. To the extent that some players exhibit strong same race preferences, they may be matched to teams with a high frequency of same-race teammates. Conditional upon the team roster, coaches may choose personnel 
combinations in which efficient passing choices occur. Such optimizing behavior does not affect the consistency of our results. It does imply, however, that our results only reflect the level of same-race bias in situations that occur in equilibrium. The average level of same race bias may be higher.

In many workplace environments, the effect of same-race bias in may not be immediately apparent or have little impact on the actors involved. The NBA differs from such instances in that player behavior is closely observed by coaches, owners, and many thousands of fans and the result of poor interracial cooperation may have an immediate effect on the outcome of the game. Also, to the extent that players derive utility from winning, they have an immediate incentive to engage in interracial cooperation.

Ultimately, our findings do not imply that efficient interracial cooperation occurs throughout the economy. They do imply, however, that interracial cooperation can occur in equilibrium when incentives are well aligned for efficient cooperation. Firms may want to consider how they can alter incentives to promote efficient cooperation among a diverse workforce. 
Table 1 - Summary Statistics

(1)

(2)

(3)

\begin{tabular}{lccc}
\hline & All Observations & Black Passer & White Passer \\
\hline Black Shooter & 0.6334 & 0.6413 & 0.6024 \\
& {$[0.0013]$} & {$[0.0014]$} & {$[0.0028]$} \\
White Shooter & 0.3666 & 0.3587 & 0.3976 \\
& {$[0.0013]$} & {$[0.0014]$} & {$[0.0028]$} \\
Position: Center & 0.0572 & 0.041 & 0.121 \\
& {$[0.0006]$} & {$[0.0006]$} & {$[0.0019]$} \\
Position: Forward & 0.2709 & 0.258 & 0.3218 \\
& {$[0.0012]$} & {$[0.0013]$} & {$[0.0027]$} \\
Position: Guard & 0.6719 & 0.701 & 0.5573 \\
& {$[0.0012]$} & {$[0.0013]$} & {$[0.0029]$} \\
First year with team & 0.1416 & 0.1464 & 0.1226 \\
& {$[0.0009]$} & {$[0.0010]$} & {$[0.0019]$} \\
Blowout game & 0.0212 & 0.0213 & 0.021 \\
& {$[0.0004]$} & {$[0.0004]$} & {$[0.0008]$} \\
Close game & 0.0649 & 0.0648 & 0.0655 \\
& {$[0.0006]$} & {$[0.0007]$} & {$[0.0014]$}
\end{tabular}

Notes: Standard deviations in brackets. Information about position and years with current team refers to the passer. Blowout game is one in which one of the teams is ahead by more than 15 points at the start of the fourth quarter. 
Table 2 - Factors Associated with the Probability that the Shooter Is White (includes group fixed effects)

\begin{tabular}{|c|c|c|c|c|c|}
\hline & (1) & (2) & (3) & (4) & (5) \\
\hline Passer is White & $\begin{array}{c}0.0097 \\
{[0.0076]}\end{array}$ & $\begin{array}{c}0.0095 \\
{[0.0076]}\end{array}$ & $\begin{array}{c}0.0119 \\
{[0.0087]}\end{array}$ & $\begin{array}{c}0.0908 \\
{[0.0867]}\end{array}$ & $\begin{array}{c}0.0035 \\
{[0.0415]}\end{array}$ \\
\hline Passer is a Center & & $\begin{array}{c}0.0009 \\
{[0.0109]}\end{array}$ & $\begin{array}{c}0.0008 \\
{[0.0109]}\end{array}$ & $\begin{array}{l}-0.2519 \\
{[0.1916]}\end{array}$ & $\begin{array}{c}0.0227 \\
{[0.0686]}\end{array}$ \\
\hline Passer is a Guard & & $\begin{array}{c}-0.0018 \\
{[0.0061]}\end{array}$ & $\begin{array}{c}-0.0017 \\
{[0.0061]}\end{array}$ & $\begin{array}{c}0.0741 \\
{[0.1349]}\end{array}$ & $\begin{array}{c}-0.008 \\
{[0.0330]}\end{array}$ \\
\hline Passer's $1^{\text {st }}$ year with team & & & $\begin{array}{c}0.0035 \\
{[0.0069]}\end{array}$ & & \\
\hline White $* 1^{\text {st }}$ year with team & & & $\begin{array}{c}-0.0152 \\
{[0.0166]}\end{array}$ & & \\
\hline Constant & $\begin{array}{c}0.3646^{* * *} \\
{[0.0015]}\end{array}$ & $\begin{array}{c}0.3658^{* * *} \\
{[0.0050]}\end{array}$ & $\begin{array}{c}0.3651^{* * *} \\
{[0.0052]}\end{array}$ & $\begin{array}{c}0.3534 * * * \\
{[0.1018]}\end{array}$ & $\begin{array}{c}0.3701 * * * \\
{[0.0275]}\end{array}$ \\
\hline $\mathrm{N}$ & 145,855 & 145,855 & 145,855 & 3,093 & 9,469 \\
\hline $\mathrm{R}^{2}$ & 0.151 & 0.151 & 0.151 & 0.594 & 0.547 \\
\hline Limit sample to: & & & & & \\
\hline Blowout situations & $\mathrm{N}$ & $\mathrm{N}$ & $\mathrm{N}$ & $\mathrm{Y}$ & $\mathrm{N}$ \\
\hline Close-games in $4^{\text {th }}$ quarter & $\mathrm{N}$ & $\mathrm{N}$ & $\mathrm{N}$ & $\mathrm{N}$ & $\mathrm{Y}$ \\
\hline
\end{tabular}

Notes: Standard errors (in brackets) are clustered at the team level. * significant at 5\%; ** significant at $1 \%$. Each regression includes a fixed effect that controls for the set of four players on the court beside the passer (34,194 groups). The fourth column is restricted to passes that occur in the fourth quarter of games in which one of the teams is ahead by more than 15 points at the start of the fourth quarter and the fifth column is restricted to observations in the fourth quarter where the teams are within four points. 
Table 3. Factors Associated with the Probability that the Shooter Is White

\begin{tabular}{|c|c|c|c|c|c|}
\hline & $(1)$ & $(2)$ & (3) & $(4)$ & (5) \\
\hline \multirow[t]{2}{*}{ Passer is White } & 0.0009 & 0.0003 & 0.003 & -0.006 & 0.0132 \\
\hline & {$[0.0051]$} & {$[0.0054]$} & {$[0.0057]$} & {$[0.0159]$} & {$[0.0101]$} \\
\hline \multirow[t]{2}{*}{ Passer is a Center } & & -0.0012 & -0.0012 & -0.0191 & 0.0112 \\
\hline & & {$[0.0053]$} & {$[0.0053]$} & {$[0.0281]$} & {$[0.0170]$} \\
\hline \multirow[t]{2}{*}{ Passer is a Guard } & & -0.0049 & -0.0048 & 0.0192 & $-0.0233 * *$ \\
\hline & & {$[0.0045]$} & {$[0.0044]$} & {$[0.0162]$} & {$[0.0085]$} \\
\hline \multirow{2}{*}{ Passer's $1^{\text {st }}$ year with team } & & & 0.0049 & & \\
\hline & & & {$[0.0038]$} & & \\
\hline \multirow[t]{2}{*}{ White $* 1^{\text {st }}$ year with team } & & & $-0.0194 * *$ & & \\
\hline & & & {$[0.0088]$} & & \\
\hline \multirow{2}{*}{$\begin{array}{l}\text { Prediction that shooter is } \\
\text { white }(\theta)\end{array}$} & 1.0272 & 1.0271 & 1.0268 & 1.0254 & 1.0373 \\
\hline & {$[0.0084]$} & {$[0.0083]$} & {$[0.0082]$} & {$[0.0411]$} & {$[0.0247]$} \\
\hline \multirow[t]{2}{*}{ Constant } & $-0.0091 * * *$ & -0.0057 & -0.0064 & -0.0136 & -0.0062 \\
\hline & [0.0029] & {$[0.0044]$} & {$[0.0044]$} & {$[0.0167]$} & {$[0.0104]$} \\
\hline Observations & 145,855 & 145,855 & 145,855 & 3,093 & 9,469 \\
\hline $\mathrm{R}^{2}$ & 0.151 & 0.151 & 0.151 & 0.594 & 0.547 \\
\hline \multicolumn{6}{|l|}{ Limit sample to: } \\
\hline Blowout situations & $\mathrm{N}$ & $\mathrm{N}$ & $\mathrm{N}$ & $\mathrm{Y}$ & $\mathrm{N}$ \\
\hline Close-games in $4^{\text {th }}$ quarter & $\mathrm{N}$ & $\mathrm{N}$ & $\mathrm{N}$ & $\mathrm{N}$ & $\mathrm{Y}$ \\
\hline
\end{tabular}

Notes: Standard errors (in brackets) are clustered at the team level. * significant at 5\%;** significant at $1 \%$. Our measure for $\theta$ comes from equation (3) on page 8 . The fourth column is restricted to passes that occur in the fourth quarter of games in which one of the teams is ahead by more than 15 points at the start of the fourth quarter and the fifth column is restricted to observations in the fourth quarter where the teams are within four points. 


\section{References}

Alesina, Alberto and Eliana La Ferrera (2005). "Ethnic Diversity and Economic Performance." Journal of Economic Literature, 43(3), 762-800.

Alesina, Alberto; Enrico Spolaore, and Romain Wacziarg (2000). "Economic Integration and Political Disintegration.” American Economic Review, 90(5), 1276-1296.

Antonovics, Kate and Brian Knight (2004). "A New Look at Racial Profiling: Evidence from the Boston Police Department." NBER working paper 10634.

Brasington, David (1999). "Joint Provision of Public Goods: The Consolidaton of School Districts." Journal of Public Economics, 73, 373-393.

Donohue, John and Steven Levitt (2001). "The Impact of Race on Policing and Arrests." Journal of Law and Economics, 44, 367-394.

Hellerstein, Judith K. and David Neumark (2008). "Workplace Segregation in the United States: Race, Ethnicity, and Skill." The Review of Economics and Statistics, 90, 459-477.

Hong, Lu and Scott Page (2004). "Groups of Diverse Problem Solvers Can Outperform Groups of High-Ability Problem Solvers." Proceedings of the National Academy of Sciences, 101(46), 16385-16389.

Kahn, Lawrence and Malav Shah (2005). "Race, Compensation and Contract Length in the NBA: 2001-2.” Industrial Relations, 44, 444-462.

Kurtulus, Fidan (2008). "The Effect of Heterogeniety on the Performance of Employees and Organizational Divisions of the Firm." Working paper, University of Massachusetts Amherst.

Luttmer, Erzo (2001). “Group Loyalty and the Taste of Redistribution.” Journal of Political Economy, 109(3), 500-528.

Martinez-Vazquez, Jorge, Mark Rider, and Mary Beth Walker (1997). "Race and the Structure of School Districts in the United States." Journal of Urban Economics, 41(2), 281-300.

Page, Scott (2007). The Difference: How the Power of Diversity Creates Better Groups, Firms, Schools, and Societies. Princeton, NJ: Princeton University Press.

Parsons, Christopher; Johan Sulaeman, Michael Yates, and Daniel Hamermesh (2008). “Strike Three: Umpires' Demand for Discrimination.” IZA discussion paper 3899. 
Price, Joseph and Wolfers, Justin (2007). "Racial Discrimination Among NBA Referees." NBER working paper 13206.

Stoll, Michael, Steven Raphael, and Harry Holzer (2004). "Black Job Applicants and the Hiring Officer's Race.” Industrial and Labor Relations Review, 57(2), 267-87.

Timmerman, Thomas (2000). "Racial diversity, age diversity, interdependence, and team performance.” Small Group Research, 31, 592-606. 